\title{
PENGARUH MOTIVASI INTRINSIK TERHADAP KEPUASAN KERJA DAN KINERJA KARYAWAN PADA PT BUSSAN AUTO FINANCE
}

\author{
I Ketut Andika Widyaputra ${ }^{1}$ \\ A.A. Sagung Kartika Dewi ${ }^{2}$ \\ ${ }^{1,2}$ Fakultas Ekonomi dan Bisnis Universitas Udayana, Bali, Indonesia \\ e-mail: andikawidyaputra8@gmail.com
}

\begin{abstract}
ABSTRAK
Kinerja merupakan hasil kerja yang dihasilkan baik dari segi kualitas maupun kuantitas pekerjaannya dan dapat dipertanggungjawabkan sesuai dengan perannya didalam organisasi atau perushaan, dan disertai dengan kemampuan, kecakapan, dan keterampilan dalam menyelesaikan pekerjaannya dalam periode waktu tertentu. Penelitian ini dilakukan pada PT Bussan Auto Finance Cabang Denpasar dengan menggunakan 73 orang karyawan sebagai responden penelitian. Teknik penentuan sampel yang digunakan dalam penelitian ini adalah teknik sampel jenuh. Pengumpulan data dilakukan melalui wawancara dan kuesioner. Teknik analisis data yang digunakan pada penelitian ini adalah path analysis yang diolah menggunakan software SPSS. Bedasarkan hasil analisis, penelitian ini menunjukan bahwa motivasi intrinsik memiliki pengaruh positif signifikan terhadap kepuasan kerja. Hal ini menunjukan bahwa pemberian motivasi intrinsik yang baik kepada karyawan dapat meningkatkan kepuasan kerja karyawan terhadap perusahaaannya. Kepuasan kerja memiliki pengaruh negatif signifikan terhadap kinerja karyawan. Semakin tinggi kepuasan kerja yang dirasakan maka semakin tinggi pula kinerja karyawan terhadap perusahaanya. Motivasi intrinsik memiliki pengaruh positif signifikan terhadap kinerja karyawan. Pemberian motivasi intrinsik yang baik kepada karyawan dapat meningkatkan kinerja karyawan terhadap perusahaaannya.
\end{abstract}

Kata kunci: motivasi intrinsik, kepuasan kerja, kinerja karyawan

\begin{abstract}
Performance is the result of work produced both in terms of quality and quantity of work and can be accounted for in accordance with its role within the organization or company, and accompanied by the ability, skill, and skill in completing the work within a certain period of time. This research was conducted at PT Bussan Auto Finance Branch of Denpasar by using 73 employees as research respondents. Sample determination technique used in this research is saturated sample technique. Data collection was done through interviews and questionnaires. Data analysis technique used in this research is path analysis processed using SPSS software. Based on the results of the analysis, this study shows that intrinsic motivation has a significant positive effect on job satisfaction. This shows that giving good intrinsic motivation to employees can increase employee work satisfaction to the company. Job satisfaction has a significant negative effect on employee performance. The higher the job satisfaction is perceived, the higher the employee's performance against his company. Intrinsic motivation has a significant positive effect on employee performance. Giving good intrinsic motivation to employees can improve employee performance against the company.
\end{abstract}

Keywords: intrinsic motivation, job satisfaction, employee performance 


\section{PENDAHULUAN}

Sumber daya manusia sangat berperan penting dalam menentukan majunya sebuah perusahaan maupun organisasi. Menurut Voon et al. (2011) sumber daya manusia merupakan aset paling penting bagi organisasi dan organisasi harus memiliki pemimpin yang mampu memimpin dan memotivasi karyawan untuk mencapai tujuan organisasi. Sumber daya manusia harus berperan aktif dan mempunyai kompetensi yang tinggi agar dapat tercapainya tujuan perusahaan. Mohammad dkk. (2010) menyatakan tingkat keberhasilan suatu perusahaan dapat dilihat dari kinerja perusahaan dalam mengelola sumber daya yang dimiliki. Perusahaan dengan kinerja yang baik, mempunyai efektivitas dalam menangani sumber daya manusianya, menentukan sasaran yang harus dacapai baik secara individu maupun organisasinya.

Menurut Thamrin (2012) kinerja karyawan didefinisinkan sebagai hasil dari upaya seseorang yang dicapai dengan adanya usaha, kemampuan, dan persepsi tugas. Upaya ini merupakan hasil dari motivasi, kepuasan, dan komitmen organisasi yang menunjukan jumlah energi (fisik dan mental) yang digunakaan seseorang individu dalam memulai tugas. Usaha adalah karakteristik individu dalam melakukan tugas. Upaya biasanya tidak langsung dipengaruhi pada periode jangka pendek. Kurniawan (2012) menyatakan kinerja karyawan sebagai prestasi kerja atau hasil kerja baik kualitas maupun kuantitas yang dicapai karyawan per periode dalam melaksanakana tugasnya sesuai dengan tanggung jawab yang diberikan kepadanya. Terdapat dua faktor yang dapat mempengaruhi kinerja karyawan yaitu faktor internal dan faktor eksternal. Faktor internal merupakan 
faktor yang berhubungan dengan sifat-sifat seseorang, meliputi sikap, sifat-sifat kepribadian, sifat fisik, keinginan atau motivasi, umur, jenis kelamin, pendidikan, pengalaman kerja, latar belakang budaya dan variable-variabel personal lainnya. Faktor eksternal merupakan faktor-faktor yang mempengaruhi kinerja karyawan yang berasal dari lingkungan, motivasi, tindakan-tindakan rekan kerja, dan lingkungan social (Lamidi, 2008).

Rendahnya kinerja karyawan dapat disebabkan oleh masalah motivasi di dalam suatu perusahaan (Cemal et al. 2012). Faktor motivasi yang akan mempengaruhi kinerja yang dimiliki seseorang merupakan potensi, dimana seseorang belum tentu bersedia untuk mengerahkan segenap potensi yang dimilikinya untuk mencapai hasil yang optimal, sehingga masih diperlukan adanya pendorong agar seseorang karyawan mau menggunakan seluruh potensinya (Cevat et al. 2012). Organisasi harus memotivasi karyawannya untuk kinerja terbaik atau untuk mencapai tujuan organisasi, bahkan motivasi adalah alat terbaik untuk meningkatkan kinerja (Zammer et al. 2014). Motivasi adalah dorongan terhadap serangkaian proses perilaku manusia pada pencapaian tujuan (Wibowo, 2011). Motivasi tidak hanya berasal dari pimpinan saja (eksternal) tapi juga pada karyawan (internal) yang digunakan untuk melancarkan pekerjaan yang ada, dengan motivasi dari diri sendiri maupun pimpinan para karyawan maka tujuan yang diinginkan oleh perusahaan bisa tercapai dengan baik, sehingga prestasi karyawan menjadi lebih meningkat (Putri, 2014).

Menurut Luthans (2011:160) motivasi intrinsik didefinisikan sebagai motivasi yang mendorong seseorang untuk berprestasi bersumber dalam diri 
individu tersebut, yang lebih dikenal dengan faktor motivasional. Wawan dan Nopiyana (2014) menyatakan bahwa motivasi yang paling kuat adalah motivasi intrinsik karena tertanam langsung di dalam diri karyawan. Melalui motivasi intrinsik membuat karyawan sadar akan tanggung jawab dan pekerjaannya yang lebih baik dan terdorong untuk semangat menyelesaikan dengan baik pekerjaannya. Hasil kerja karena kesadaran menciptakan kinerja yang baik dan karyawan akan sadar bahwa dengan memiliki kinerja yang baik, ia akan dapat memenuhi kebutuhan hidupnya. Hal ini sesuai dengan penelitian yang dilakukan oleh Lukito dkk. (2016) yang menunjukkan bahwa motivasi instrinsik berpengaruh positif terhadap kinerja karyawan. Hal ini berarti bahwa bila motivasi instrinsik ditingkatkan, maka kinerja karyawan meningkat. Hasil penelitian tersebut mendukung hasil penelitian Risqi dkk. (2016) menunjukan bahwa motivasi intrinsik berpengaruh positif dan signifikan terhadap kinerja karyawan.

Selain motivasi, kepuasan kerja juga menjadi salah satu faktor dalam meningkatkan kinerja karyawan. Ishfaq et al. (2010) menyatakan karyawan akan termotivasi dengan terpenuhinya kepuasan kerja atau rasa keberhasilan dalam menyelesaikan suatu pekerjaan. Naeem et al. (2014) menyatakan kepuasan kerja sangat penting adanya dalam organisasi karena memiliki dampak yang signifikan. Karyawan dengan kepuasan kerja yang tinggi diharapkan membuatnya menjadi semakin termotivasi, merasa senang dalam bekerja dan nantinya tujuan perusahaan akan tercapai. Shurbagi (2014) berpendapat bahwa kepuasan kerja merupakan cara pandang seseorang baik yang bersifat positif maupun negatif tentang pekerjaannya. Karyawan yang memiliki kepuasan kerja yang tinggi 
mengakibatkan karyawan tersebut akan menjadi semakin setia kepada organisasi, termotivasi, merasa senang dalam bekerja, dan pada akhirnya akan tercapai tujuan perusahaan. Sedangkan karyawan yang merasa tidak puas cenderung menghindar dari tugas dan tanggung jawab, sehingga dapat mengganggu proses pencapaian tujuan perusahaan (Indrawan dan Kartika Dewi, 2014). Penelitian yang dilakukan oleh Dhermawan dkk. (2012) menunjukan kepuasan kerja berpengaruh signifikan terhadap kinerja pegawai. Hal tersebut menunjukkan bahwa semakin baik kepuasan kerja yang dirasakan oleh pegawai, maka akan semakin baik pula kinerja pegawai tersebut. Hasil penelitian ini bertolak belakang dengan hasil penelitian Henis dkk. (2016) yang menyatakan bahwa kepuasan kerja karyawan tidak berpengaruh signifikan terhadap kinerja karyawan pada PDAM Kota Malang.

PT Bussan Auto Finance (BAF) merupakan perusahaan yang bergerak dibidang jasa pembiayaan dengan berkosentrasi kepada pembiayaan sepeda motor Yamaha. Seiring pertumbuhan dan perkembangan kebutuhan masyarakat, PT Bussan Auto Finance turut berinovasi untuk menjadi solusi bagi pembiayaan kebutuhan masyarakat dengan membuka berbagai macam jenis pembiayaan lainnya seperti pembiayaan multiproduk, mesin pertanian, mobil dan juga pembiayaan kembali. PT Bussan Auto Finance Cabang Denpasar berlokasi di Jl. Gatot Subroto Timur No. 231 AB. Denpasar.

Fenomena yang terjadi pada PT Bussan Auto Finance Cabang Denpasar adalah masalah kinerja karyawan. Berdasarkan hasil wawancara terhadap sepuluh orang karyawan dengan berpedoman pada indikator kinerja karyawan menurut 
Mangkunegara (2011:13) yaitu prestasi kerja, dimana masih rendahnya prestasi kerja yang dicapai karyawan PT Bussan Auto Finance. Hal ini dapat dilihat dari persentase pencapaian target bagian marketing dan collection pada tahun 20142016 yang belum memenuhi target yang telah ditetapkan oleh perusahaan.

Faktor yang dapat mempengaruhi perilaku kinerja karyawan diantaranya adalah motivasi intrinsik dan kepuasan kerja. Murty dan Hudiwinarsih (2012) menyatakan bahwa seseorang karyawan yang termotivasi akan bersifat energik dan bersemangat, dan sebaliknya seseorang karyawan dengan motivasi yang rendah akan sering menampilkan rasa tidak nyaman dan tidak senang terhadap pekerjaannya yang mengakibatkan kinerja mereka menjadi buruk dan tujuan perusahaan tidak akan tercapai.

Berikut adalah uraian beberapa indikator yang menunjukkan bahwa ada permasalahan pada motivasi intrinsik berdasarkan hasil wawancara terhadap sepuluh orang karyawan dengan berpedoman pada indikator motivasi intrinsik menurut Luthans (2011:160) yaitu: Recognition (pengakuan), Kurangnya pengakuan pimpinaan atas hasil kerja yang telah dicapai karyawannya. Pengakuan adalah suatu bentuk umpan balik atas hasil kerja yang telah diraih. Pengakuan tidak hanya bertujuan untuk menghargai kinerja karyawan, tetapi juga untuk motivasi karyawan untuk lebih meningkatkan kinerjanya. Advacement (pengembangan), Kurangnya kesempatan promosi yang diberikan diberikan pimpinan terhadap karyawannya. Selain menghargai kinerja bagus dari karyawan, promosi juga bertujuan mengembangkan keterampilan karyawan sehingga dengan 
diberikannya kesempatan promosi kepada karyawan akan memotivasi karyawan untuk lebih meningkatkan kinerjanya.

Sedangkan faktor motivasi ekstrinsik yang diterima karyawan sudah sesuai dengan beban kerja yang diterima karyawan. Motivasi ekstrinsik menurut Luthans (2011:160) adalah motivasi yang bersumber dari luar diri yang turut menentukan perilaku seseorang dalam kehidupan seseorang yang dikenal dengan teori hygiene faktor.

Penurunan kinerja karyawan juga disebabkan karena masih kurangnya kepuasan kerja yang dirasakan karyawan. Apabila karyawan tidak merasakan kepuasan kerja, maka akan muncul tingkat kinerja yang rendah karena tidak adanya niat untuk berusaha bekerja lebih maksimal (Riswanto, 2015). Salah satu indikator kepuasan kerja yaitu indikator kesempatan promosi. Bedasarkan hasil wawancara terhadap sepuluh orang karyawan dimana ditemukan indikasi rendahnya kepuasan kerja karyawan pada perusahaan dikarenakan masih kurangnya kesempatan promosi yang diberikan pimpinan terhadap karyawannya. Promosi merupakan faktor yang mampu memotivasi bagi karyawan sehingga dengan diberikannya kesempatan promosi bagi karyawan akan mendorong karyawan untuk terus meningkatkan kinerjanya dalam bekerja.

Sejumlah penelitian telah dilakukan untuk mengetahui pengaruh motivasi intrinsik terhadap kepuasan kerja. Hasil penelitian Eka (2016), Stringer et al. (2011), Bahrulmazi et al. (2013) Budianto dkk. (2013) serta Putra (2013) menunjukkan bahwa adanya pengaruh positif antara motivasi intrinsik terhadap 
kepuasan kerja. Bedasarkan dari penelitian-penelitian di atas, maka dapat diajukan hipotesis sebagai berikut.

$\mathrm{H}_{1}$ : Motivasi intrinsik berpengaruh positif signifikan terhadap kepuasan kerja.

Sejumlah penelitian telah dilakukan untuk mengetahui pengaruh kepuasan kerja terhadap kinerja karyawan. Hasil penelitian Indrawati (2013), Parwanto dan Wahyudin (2011), Devi (2009), Dhermawan dkk. (2012), Satyawati dan Suartana (2014), serta Novita dkk. (2016) menunjukan kepuasan kerja berpengaruh signifikan terhadap kinerja pegawai. Hal tersebut menunjukkan bahwa semakin baik kepuasan kerja yang dirasakan oleh pegawai, maka akan semakin baik pula kinerja pegawai tersebut. Bedasarkan dari penelitian-penelitian di atas, maka dapat diajukan hipotesis sebagai berikut.

$\mathrm{H}_{2}$ : Kepuasan kerja berpengaruh positif signifikan terhadap kinerja karyawan

Sejumlah penelitian telah dilakukan untuk mengetahui pengaruh motivasi intrinsik terhadap kinerja karyawan. Hasil penelitian Lukito dkk. (2016), Risqi dkk. (2016), Maulana dkk. (2015), Budiharjo dan Sanjaya (2016), Fernadi dkk. (2016) serta Wawan dan Nopiyana (2014) menunjukan bahwa motivasi intrinsik berkorelasi positif dan signifikan terhadap kinerja karyawan. Hal ini menunjukkan bahwa semakin besar motivasi intrinsik seseorang, semakin besar juga kinerja karyawan tersebut. Bedasarkan dari penelitian-penelitian di atas, maka dapat diajukan hipotesis sebagai berikut.

$\mathrm{H}_{3}$ : Motivasi intrinsik berpengaruh positif signifikan terhadap kinerja karyawan.

Berdasarkan hasil kajian empiris atau penelitian terdahulu, maka dapat di gambarkan kerangka konseptual sebagai berikut. 


\section{Gambar 1. Model Konseptual Penelitian}

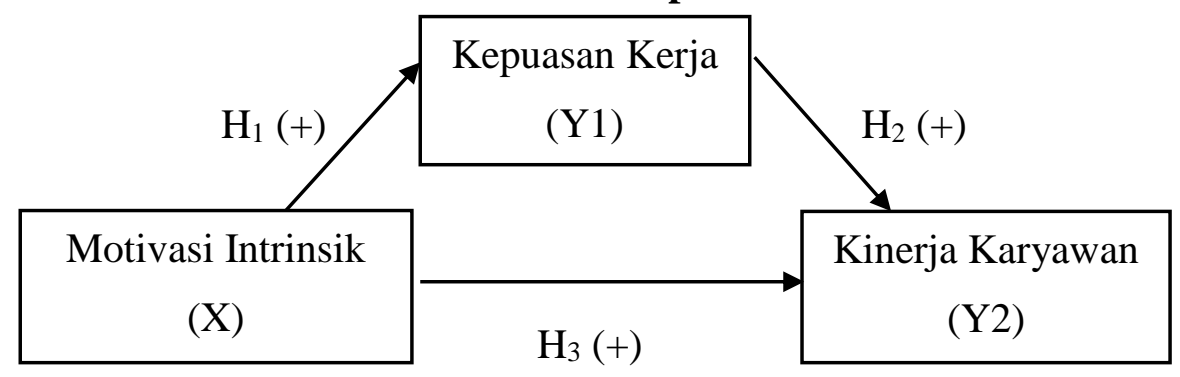

Sumber: Data Diolah, 2017

\section{METODE PENELITIAN}

Penelitian ini menggunakan dua variable dependent yaitu kepuasan kerja dan kinerja karyawan, serta satu variable independent yaitu motivasi intrinsik. Berdasarkan permasalahan dalam penelitian ini, desain penelitiannya digolongkan pada jenis penelitian asosiatif (hubungan) karena dalam penelitian ini mempunyai tujuan untuk mengetahui pengaruh sebab akibat dari variabel-variabel yang diteliti. Lokasi penelitian ini dilakukan di PT Bussan Auto Finance Cabang Denpasar yang berkedudukan di J1. Gatot Subroto Timur No. 231 AB Denpasar.

Subjek penelitian yang digunakan dalam penelitian ini adalah karyawan pada PT. Bussan Auto Finance Cabang Denpasar. Obyek penelitian akan meneliti apakah ada pengaruh yang signifikan antara motivasi intrinsik terhadap kepuasan kerja dan kinerja karyawan pada PT Bussan Auto Finance Cabang Denpasar. Penelitian ini bertujuan untuk mengidentifikasi pengaruh motivasi intrinsik terhadap kepuasan kerja dan kinerja karyawan. Berdasarkan pokok permasalahan dan hipotesis yang diajukan, variabel-variabel dalam analisis ini dapat diidentifikasi variabel independen adalah motivasi intrinsik (X). Variabel dependen adalah kepuasan kerja $\left(\mathrm{Y}_{1}\right)$ kinerja karyawan $\left(\mathrm{Y}_{2}\right)$. 
Jenis data yang digunakan dalam penelitian ini adalah data kuantitatif dan data kualitatif. Data kuantitatif dalam penelitian ini berupa pendapat responden terhadap pernyataan yang meliputi motivasi intrinsik, kepuasan kerja dan kinerja karyawan pada PT Bussan Auto Finance Cabang Denpasar. Data kualitatif pada penelitian ini berupa gambaran umum dan sejarah PT Bussan Auto Finance Cabang Denpasar. Penelitian ini juga menggunakan dua sumber data yaitu data primer dan data sekunder. Data primer dalam penelitian ini adalah data yang diperoleh melalui hasil kuesioner yang disebarkan kepada karyawan PT Bussan Auto Finance Cabang Denpasar. Data sekunder dalam penelitian ini adalah data jumlah karyawan dan sejarah perusahaan. Jumlah populasi relatif kecil, yaitu 73 atau di bawah 100, maka seluruh anggota populasi diambil sebagai sampel penelitian. Metode pengumpulan data yang digunakan dalam penelitian ini adalah dengan wawancara dan kuesioner.

Penelitian ini menggunakan analisis statistik deskriptif. Analisis statistik deskriptif yang dipakai dalam penelitian ini adalah nilai rata-rata, nilai minimum, nilai maksimum. Teknik analisis yang digunakan pada penelitian ini adalah teknik analisis jalur (Path Analysis). Menurut Utama (2011:156), analisis jalur merupakan perluasan dari analisis regresi linier berganda, untuk menaksir hubungan kualitas antara variabel yang berjenjang berdasarkan teori.

Substruktur 1

$$
\mathrm{Y}_{1}=\alpha+\rho_{1} \mathrm{X}+\mathrm{e}_{1}
$$

Keterangan :

Y1 = Kepuasan kerja

$\alpha \quad=$ Nilai konstanta

$\rho_{1} \quad=$ Koefisien regresi variabel motivasi intrinsik pada kepuasan kerja 
$\begin{array}{ll}\mathrm{X} & =\text { Motivasi intrinsik } \\ \mathrm{e}_{1} & =\text { error } \text { of term } \text { atau variabel pengganggu }\end{array}$

Substruktur 2

$$
\mathrm{Y}_{2}=\alpha+\rho_{2} \mathrm{X}+\rho_{3} \mathrm{Y} 1+\mathrm{e}_{2}
$$

Keterangan :

$\mathrm{X}=$ Variable motivasi intrinsik

Y1 = Variable kepuasan kerja

Y2 = Variabel kinerja karyawan

$\alpha \quad=$ Nilai konstanta

$\rho_{2} \quad=$ Koefisien regresi variabel motivasi intrinsik berpengaruh langsung terhadap kinerja karyawan

$\rho_{3} \quad=$ Koefisien regresi variabel kepuasan kerja berpengaruh langsung terhadap kinerja karyawan

$\mathrm{e}_{2}=$ error of term atau variabel pengganggu

\section{HASIL DAN PEMBAHASAN}

Pengujian data penelitian ini menggunakan teknik analisis jalur. Langkahlangkahnya adalah sebagai berikut.

Tabel 1.

Hasil Analisis Jalur (Regresi Substruktur 1) X terhadap Y1

\begin{tabular}{llll}
\hline Model & $\begin{array}{l}\text { Standardized Coefficients } \\
\text { Beta }\end{array}$ & T & Sig \\
\hline Motivasi intrinsic & 0,860 & 14,192 & 0,000 \\
\hline R square & $: 0,739$ & & \\
F.statistic & $: 201,416$ & \\
Constant & $: 2,543$ & \\
Sig. F & $: 0,000$ & \\
\hline
\end{tabular}

Sumber: Data Diolah, 2017

Berdasarkan hasil analisis jalur substruktur 1 seperti yang disajikan pada

Tabel 1, maka persamaan strukturalnya adalah sebagai berikut.

$$
\mathrm{Y} 1=\beta_{1} \mathrm{X}+\mathrm{e}_{1}
$$




$$
\mathrm{Y} 1=0,860 \mathrm{X}+\mathrm{e}_{1}
$$

Persamaan regresi tersebut dapat diartikan yaitu variabel $\mathrm{X}$ memiliki koefisien regresi sebesar 0,860 berarti motivasi intrinsik memiliki pengaruh positif terhadap kepuasan kerja.

Berdasarkan hasil analisis jalur substruktur 2 seperti yang disajikan pada Tabel 2 maka persamaan strukturalnya adalah sebagai berikut.

$$
\begin{gathered}
\mathrm{Y} 2=\beta_{2} \mathrm{X}+\beta_{3} \mathrm{Y} 1+\mathrm{e}_{1} \\
\mathrm{Y} 2=0,346 \mathrm{X}+0,474 \mathrm{Y} 1+\mathrm{e}_{1}
\end{gathered}
$$

Tabel 2.

Hasil Analisis Jalur (Regresi Substruktur 2) X dan Y1 terhadap Y2

\begin{tabular}{llll}
\hline Model & $\begin{array}{l}\text { Standardized Coefficients } \\
\text { Beta }\end{array}$ & T & Sig \\
\hline Motivasi Intrinsik & 0,346 & 2,418 & 0,018 \\
Kepuasan Kerja & 0,474 & 3,314 & 0,001 \\
\hline R square & $: 0,627$ & & \\
F.statistic & $: 58,728$ & \\
Constant & $: 3,200$ & & \\
Sig. F & $: 0,000$ & & \\
\hline
\end{tabular}

Sumber: Data Diolah, 2017

Persamaan regresi tersebut dapat diartikan yaitu variabel $\mathrm{X}$ memiliki koefisien regresi sebesar 0,346 berarti motivasi intrinsik memiliki pengaruh positif terhadap kinerja karyawan. Variabel Y1 memiliki koefisien regresi sebesar 0,474 berarti kepuasan kerja memiliki pengaruh positif kinerja karyawan.

Hipotesis 1 dapat dirumuskan $\mathrm{H} 0: \beta_{1}=0$ artinya motivasi intrinsik tidak memiliki pengaruh positif terhadap kepuasan kerja. H1: $\beta_{1}>0$ artinya motivasi intrinsik memiliki pengaruh positif terhadap kepuasan kerja. Hipotesis 2 dapat dirumuskan H0: $\beta_{2}=0$ artinya kepuasan kerja tidak memiliki pengaruh positif 
terhadap kinerja karyawan. $\mathrm{H} 2: \beta_{2}<0$ artinya kepuasan kerja memiliki pengaruh positif terhadap kinerja karyawan. Hipotesis 3 dapat dirumuskan $\mathrm{H} 0: \beta_{3}=0$ artinya motivasi intrinsik tidak memiliki pengaruh positif terhadap kinerja karyawan. H3: $\beta_{3}<0$ artinya motivasi intrinsik memiliki pengaruh positif terhadap kinerja karyawan.

Berdasarkan hasil analisis pengaruh $\mathrm{X}$ terhadap $\mathrm{Y} 2$ diperoleh nilai Sig. $\mathrm{t}$ sebesar 0,018 dengan nilai koefisien beta 0,346. Nilai Sig. t 0,018<0,05 mengindikasikan bahwa $\mathrm{H}_{0}$ ditolak dan $\mathrm{H}_{3}$ diterima. Hasil ini mempunyai arti bahwa motivasi intrinsik memiliki pengaruh positif signifikan terhadap kinerja karyawan.

Besarnya pengaruh variabel motivasi intrinsik terhadap kepuasan kerja dan kinerja karyawan secara parsial dilihat dari nilai Standardized Coeficient Beta adalah sebagai berikut. Pengaruh variabel motivasi intrinsik terhadap kepuasan kerja sebesar 0,860. Pengaruh variabel kepuasan kerja terhadap kinerja karyawan sebesar 0,474. Pengaruh variabel motivasi intrinsik terhadap kinerja karyawan sebesar 0,346.

Pengaruh variabel motivasi intrinsik terhadap kinerja karyawan melalui kepuasan kerja.

$$
\begin{aligned}
\mathrm{X} \rightarrow \mathrm{Y} 1 \rightarrow \mathrm{Y} 2 & =(\mathrm{P} 1 \times \mathrm{P} 2) \\
& =(0,860 \times 0,474 .)=0,407
\end{aligned}
$$

Pengaruh total $=$ pengaruh langsung + pengaruh tidak langsung. Pengaruh motivasi intrinsik terhadap kinerja karyawan melalui kepuasan kerja $=0,346+0,407=0,753$ 
Berdasarkan hasil penelitian terhadap pengujian hipotesis, ditemukan bahwa motivasi intrinsik berpengaruh positif dan signifikan terhadap kepuasan kerja. Hal ini berarti bahwa jika pemberian motivasi intrinsik yang diberikan terhadap karyawan baik seperti memberikan kesempatan kepadanya agar karyawan dapat berusaha mencapai hasil, pengakuan, pekerjaan itu sendiri, tanggung jawab, dan pengembangan, maka kepuasan kerja karyawan terhadap perusahaannya akan semakin tinggi.

Hasil pengujian hipotesis 1 ini sejalan dengan hasil penelitian yang dilakukan sebelumnya oleh Eka (2016), Stringer et al., (2011), Bahrulmazi et al. (2013), Budianto, dkk. (2013), Putra (2013) yang menyatakan bahwa motivasi intrinsik memiliki pengaruh positif dan signifikan terhadap kepuasan kerja. Berdasarkan hasil penelitian terhadap pengujian hipotesis, ditemukan bahwa kepuasan kerja berpengaruh positif dan signifikan terhadap kinerja karyawan.

Hasil pengujian hipotesis 2 ini sejalan dengan hasil penelitian yang dilakukan sebelumnya oleh Indrawati (2013), Wahyudin (2011), Devi (2009), Dhermawan, dkk (2012), Satyawati dan Suartana (2014), Novita, dkk (2016) yang menyatakan bahwa kepuasan kerja memiliki pengaruh positif dan signifikan terhadap kinerja karyawan.

Berdasarkan hasil penelitian 3 terhadap pengujian hipotesis, ditemukan bahwa motivasi intrinsik berpengaruh positif dan signifikan terhadap kinerja karyawan. Hal ini berarti bahwa jika pemberian motivasi intrinsik yang diberikan terhadap karyawan baik seperti memberikan kesempatan kepadanya 
agar karyawan dapat berusaha mencapai hasil, pengakuan, pekerjaan itu sendiri, tanggung jawab, dan pengembangan, maka kinerja karyawan terhadap perusahaan akan semakin tinggi.

Hasil pengujian hipotesis 4 ini sejalan dengan hasil penelitian yang dilakukan sebelumnya oleh Lukito, dkk (2016), Risqi, dkk. (2016), Maulana, dkk (2015), Budiharjo dan Sanjaya (2016), Fernadi, dkk. (2016), Wawan dan Nopiyana (2014) yang menyatakan bahwa motivasi intrinsik memiliki pengaruh positif dan signifikan terhadap kinerja karyawan.

\section{KESIMPULAN DAN SARAN}

Berdasarkan hasil analisis penelitian dan hasil pembahasan pada bab sebelumnya maka simpulan dari penelitian ini adalah motivasi intrinsik memiliki pengaruh positif signifikan terhadap kepuasan kerja karyawan pada PT Bussan Auto Finance Cabang Denpasar. Pemberian motivasi intrinsik yang baik kepada karyawan dapat meningkatkan kepuasan kerja karyawan. Kepuasan kerja memiliki pengaruh positif signifikan terhadap kinerja karyawan pada PT Bussan Auto Finance Cabang Denpasar. Tingkat kepuasan kerja yang dirasakan oleh karyawan dapat meningkatkan kinerja karyawan, sehingga semakin tinggi kepuasan kerja yang dirasakan maka semakin tinggi pula kinerja karyawan. Motivasi intrinsik memiliki pengaruh positif signifikan terhadap kinerja karyawan pada PT Bussan Auto Finance Cabang Denpasar. Pemberian motivasi intrinsik yang baik kepada karyawan dapat meningkatkan kinerja karyawan. Motivasi Intrinsik berpengaruh positif signifikan terhadap kinerja karyawan melalui 
I Ketut Andika Widyaputra, Pengaruh Motivasi Intrinsik...

mediasi kepuasan kerja karyawan pada PT Bussan Auto Finance Cabang Denpasar. Hal ini menunjukan semakin tinggi motivasi intrinsik, maka semakin tinggi kinerja karyawan dan menyebabkan kepuasan kerja karyawan semakin meningkat.

Saran yang dapat diberikan, berdasarkan pada hasil analisis, pembahasan dan simpulan adalah perusahaan sebaiknya memperhatikan pemberian motivasi intrinsik terhadap karyawannya khususnya dalam memberikan kesempatan untuk mencapai prestasi kerja sehingga mendorong semangat karyawan dalam bekerja. Perusahaan juga sebaiknya memberikan kepercayaan kepada karyawan sehingga mendorong karyawan dalam menyelesaikan pekerjaan tepat waktu, dengan demikian karyawan di harapkan mampu bertahan dan loyal terhadap perusahaan. Perusahaan juga sebaiknya memberikan tugas yang bervariasi kepada karyawan untuk mendorong karyawan lebih berkembang. Perusahaan sebaiknya memperhatikan kepuasan kerja yang dimiliki oleh karyawannya. Meningkatkan kepuasan kerja terhadap karyawan dapat dilakukan dengan cara memberikan upah sesuai dengan beban kerja dan tanggung jawab karyawan di perusahaan. Perusahaan juga sebaiknya memberikan kesempatan kepada karyawan untuk memperoleh promosi, sehingga hal tersebut dapat memotivasi karyawan dalam meningkatkan kinerjanya. Perusahaan sebaiknya lebih memperhatikan dan meningkatkan kinerja yang dimiliki oleh karyawannya. Meningkatkan kinerja karyawan dapat dilakukan dengan cara memperhatikan inisiatif yang dimiliki karyawan serta tingkat kesalahan kerja, hal tersebut dapat dilihat dari penyelesaian pekerjaan oleh karyawan yang tidak sesuai dengan ketentuan yang 
ditetapkan, sehingga nantinya karyawan dapat lebih meningkatkan kinerjanya dan memberikan manfaat bagi perusahaan.

\section{REFERENSI}

Bahrulmazi, Benjamin, Behrooz, \& Thiam. 2013. The Effectiveness of Intrinsic and Extrinsic Motivations: A Study of Malaysian Amway Company's Direct Sales Forces. International Journal of Business and Social Science, 4(9):96103.

Budianto, Ferdinand, dan Roby Sambung. 2013. Pengaruh Motivasi Intrinsik dan Motivasi Ekstrinsik Terhadap Kinerja Pegawai Melalui Kepuasan Kerja (Studi Pada Universitas Palangka Raya). JSM (Jurnal Sains Manajemen), 2(2):78-88.

Budiharjo, Jehoshaphat Tanujayaputra., Sanjaya, Steven. 2016. Analisis Hubungan Motivasi Intrinsik Dan Ekstrinsik Terhadap Kinerja Karyawan Di Hotel Swiss-Belinn Tunjungan Surabaya. Jurnal Manajemen Perhotelan, Fakultas Ekonomi, Universitas Kristen Petra, 4(2):424-435.

Cemal Zehir, Bursa Muceldili, dan Songul Sehir. 2012. The Moderating Effect of Ethical Climate on the Relationship between Job Satisfaction and Organizational Commitment: Evidence from Large Companies in Turkey. Journal Social And Behavioral Science, 5(8):734-743.

Cevat Celep, Ozge Eler Yilmazturk. 2012. The Relationship Among Organizational Trust, Multidimensional Organizational Commitment and Perceived Organizational Support In Educational Organizations. Journal Social and Behavioral Sciences, 4(6):5763-5776.

Eka Rosita Widya Sariningtyas. 2016. Analisis Karakteristik Individu dan Motivasi Intrinsik Terhadap Komitmen Organisasi dengan Kepuasan Kerja Sebagai Variabel Intervening (Studi Pada Pdam Tirta Mulia Kabupaten Pemalang). Serat Acitya- Jurnal Ilmiah UNTAG Semarang, 5(1): 55-72.

Dhermawan, Anak Agung Ngurah Bagus., Adnyana Sudibya, I Gede., Mudiartha Utama., I Wayan. 2012. Pengaruh Motivasi, Lingkungan Kerja, Kompetensi, dan Kompensasi terhadap Kepuasan Kerja dan Kinerja Pegawai Di Lingkungan Kantor Dinas Pekerjaan Umum Provinsi Bali. Jurnal Manajemen, Strategi Bisnis, dan Kewirausahaan, 6(2):173-184.

Eka Rosita Widya Sariningtyas. 2016. Analisis Karakteristik Individu dan Motivasi Intrinsik Terhadap Komitmen Organisasi dengan Kepuasan Kerja 
Sebagai Variabel Intervening (Studi Pada Pdam Tirta Mulia Kabupaten Pemalang). Serat Acitya- Jurnal Ilmiah UNTAG Semarang, 5(1):55-72.

Fernadi, Ahmad Dedi., Wahyu, Dwi., dan Hidayati, Noor. 2016. Pengaruh Gaya Kepemimpinan Transformasional, Motivasi Intrinsik dan Motivasi Ekstrinsik Terhadap Kinerja Karyawan Pada Perusahaan Daerah Air Minum (PDAM) Kabupaten Tanah Laut. Jurnal Bisnis dan Pembangunan, 5(2):4150.

Henis Fiqih Amalini, Mochammad Al Musadieq, Tri Wulida Afrianty. 2016. Pengaruh Locus Of Control Terhadap Kepuasan Kerja dan Kinerja (Studi Pada Karyawan Perusahaan Daerah Air Minum (Pdam) Kota Malang). Jurnal Administrasi Bisnis (JAB), 35(1):68-77.

Indrawan, Dewa Cahyadi Dan Kartika Dewi, A.A. Sagung. 2014. Pengaruh Kompensasi. Kepemimpinan, Dan Lingkungan Kerja Fisik Terhadap Kepuasan Kerja Karyawan PT. Cargo Asas International, Denpasar. EJurnal Manajemen Universitas Udayana, 3(6):1767-1779.

Indrawati, Ayu Desi. 2013. Pengaruh Kepuasan Kerja terhadap Kinerja Karyawan dan Kepuasan Pelanggan pada Rumah Sakit Swasta Di Kota Denpasar. Jurnal Manajemen, Strategi Bisnis, dan Kewirausahaan, 7(2):135-142.

Ishfaq Ahmed, Muhamad Nawaz, Musarrat, Naveed Iqbal, Imran Ali, Zeeshan Shaukat, Ahmad Usman. 2010. Effect of Motivation Factors on employees Job satisfaction: a Case Study of University of The Punjab Pakistan. International Journal Of Business and Managemen, 5(3):70-80.

Kurniawan, Dedi. 2012. Pengaruh Budaya Kerja dan Motivasi Kerja Terhadap Kinerja Karyawan (IFRC) Banda Aceh. Jurnal Manajemen Pascasarjana Universitas Syiah Kuala, 1(1):1-15.

Lamidi. 2008. Pengaruh Kepemimpinan Transformasional terhadap Organization Citizenship Behavior: Dengan Variabel Intervening Komitmen Organisasional. Jurnal Ekonomi dan Kewirausahaan, 8(1):25-37.

Lukito, Heri Puspito., Haryono, Andi Tri., Warso, M Mukeri. 2016. Pengaruh Motivasi Instrinsik, Motivasi Ekstrinsik dan Pegalaman Kerja terhadap Kinerja Karyawan (Studi Pada Btpn Syariah Semarang). Journal of Management, 2(2):1-15.

Luthans, Fred. 2011. Perilaku Organisasi. Cetakan Keempat. Yogyakarta: Penerbit Andi Offset.

Mangkunegara, A. P. 2011. Manajemen Sumber Daya Manusia Perusahaan. Bandung: PT Remaja Rosdakarya. 
Maulana., Fakhrian Harza., Hamid, Djamhur., Mayoan, Yuniadi. 2015. Pengaruh Motivasi Intrinsik, Motivasi Ekstrinsik Dan Komitmen Organsasi terhadap Kinerja Karyawan Pada Bank Btn Kantor Cabang Malang. Jurnal Administrasi Bisnis (JAB), 22(1):1-8.

Mohammad Syibli, Indung Sudarso dan Udisubakti Ciptomulyono. 2010. Analisis pengaruh faktor-faktor rekrutmen terhadap kinerja SDM Outsourcing PT Telkom dengan pendekatan SEM (Structural Equation Modelling). Jurnal Pasca Sarjana Magister Manajemen Teknologi-ITS, Kampus ITS Surabaya, $: 1-10$.

Murty Windy Aprilia., Hundiwinarsih Gunasti. 2012. Pengaruh Kompensasi, Motivasi dan Komitmen Organisasi Terhadap Kinerja Karyawan bagian Akutansi (studi kasus pada perusahaan manufaktur di Surabaya). Jurnal The Indonesian Accounting Review, 2(2):64-70.

Naeem, AT., Freeha Ihsan and Zahid Mahmood. 2014. The study of Organizational justice, violation of psychological contract and its effect on job satisfaction in Paris Indrustry of Pakistan. International Journal of Academy Research in Business and Social Sciense. 4(12):244-251.

Novita, Bambang Swasto Sunuharjo, Ika Ruhana. 2016 Pengaruh Kepuasan Kerja dan Komitmen Organisasional terhadap Kinerja Karyawan (Studi Pada Pt. Telekomunikasi Indonesia, Tbk Witel Jatim Selatan, Malang). Jurnal Administrasi Bisnis (JAB), 34(1):38-46.

Parwanto dan Wahyuddin. 2011. Pengaruh Faktor- Faktor Kepuasan Kerja terhadap Kinerja Karyawan Pusat Pendidikan Komputer Akuntansi Imka D1 Surakarta. Skripsi.(Online) (diakses 7 Februari 2012).

Patrick, H.A. and Kumar, A. 2011. Career Management, Employee Development and Performance in Indian Information Technology Organization. Business Management Dynamics, 1(5):24-31.

Putra, Aditya Kamajaya. 2013. Pengaruh Motivasi Intrinsik dan Motivasi Ekstrinsik terhadap Kepuasan Kerja, Jurnal Ilmu Manajemen, 1(1):377-387.

Putri, A.L. (2014). Hubungan motivasi dengan komitmen organisasi: kasus pada karyawan pada PT. Sucofindo cabang Dumai. Jom FISIP, 1(2):1-15.

Riswanto, Eka. 2015. Pengaruh Komitmen Organisasi terhadap Kinerja Melalui Kepuasan Kerja karyawan Pada Bank Artha Graha International Tbk Pekanbaru. Jurnal Online Mahasiswa (JOM) FEKON, 1(5):1-15. 
Satyawati., Ni Made Ria dan Suartana., I Wayan. 2014. Pengaruh Gaya Kepemimpinan dan Budaya Organisasi terhadap Kepuasan Kerja yang Berdampak pada Kinerja Keuangan. E-Jurnal Akuntansi Universitas Udayana, 6(1):17-32.

Shurbagi, Adel. 2014. The Relationship between Transfornational Leadership Style Job Satisfaction and The Effect of Organizational Commitment. International Business Research, 7(11):126-138.

Stringer, Carolyn., Jeni Didham, Paul Theivananthampillai. 2011. Motivation, Pay Satisfaction, and Job Satisfaction of Front-Line Employees. Qualitative Research in Accounting \& Management, 8(2):161-179.

Thamrin H.M. 2012. The Influence of Tranformational Leadership and Organizational Commitment on Job Satisfaction and Employee Performance. International Journal of Innovation, Management and Technology, 3(5):566-572.

Utama, M. S. 2011. Aplikasi Analisis Kuantitatif. Edisi Kelima. Diktat Kuliah Pada Fakultas Ekonomi Universitas Udayana.

Voon, M.L., Lo, M.C., Ngui, K.S. dan Ayob, N.B. 2011. The influence of Leadership Styles on Employee Job Satisfaction in Public Sector Organization Malaysia. International Journal of Business, Management and Social Science, 2(1):24-32.

Wawan Prahiawan dan Nopiyana Simbolon. 2014. Pengaruh Motivasi Intrinsik dan Lingkungan Kerja terhadap Kinerja Karyawan Pada Pt Intimas Lestari Nusantara. Jurnal Ekonomi. 5(1):35-41.

Wibowo. 2011. Manajemen Kinerja, Edisi Ketiga. Jakarta: PT Rajagrafindo Persada

Zammer Hashim, Shehzad Ali Waqar Nisar Muhammad Amir. 2014. The Impact of the Motivation on the Employee's Performance in Beverage Industry of Pakistan International. Journal of Academic. Research in Accounting, Finance and Management Sciences. 4(1):239-298. 